\title{
Cloning and Expression of a Novel Member of the Low Voltage- Activated T-Type Calcium Channel Family
}

\author{
Jung-Ha Lee, ${ }^{1}$ Asif N. Daud, ${ }^{1}$ Leanne L. Cribbs, ${ }^{1}$ Antonio E. Lacerda, ${ }^{2}$ Alexei Pereverzev, ${ }^{3}$ Udo Klöckner, ${ }^{4}$ \\ Toni Schneider, ${ }^{3}$ and Edward Perez-Reyes ${ }^{1}$ \\ ${ }^{1}$ Department of Physiology, Loyola University Medical Center, Maywood, Illinois 60153, 2Rammelkamp Center for \\ Research and Education, MetroHealth Medical Center, Cleveland, Ohio 44109, and Departments of ${ }^{3}$ Physiology and \\ ${ }^{4}$ Vegetative Physiology, University of Cologne, D50931 Cologne, Germany
}

Low voltage-activated $\mathrm{Ca}^{2+}$ channels play important roles in pacing neuronal firing and producing network oscillations, such as those that occur during sleep and epilepsy. Here we describe the cloning and expression of the third member of the T-type family, $\alpha 1 \mathrm{l}$ or $\mathrm{Ca}_{\mathrm{v}} \mathrm{T} .3$, from rat brain. Northern analysis indicated that it is predominantly expressed in brain. Expression of the cloned channel in either Xenopus oocytes or stably transfected human embryonic kidney-293 cells revealed novel gating properties. We compared these electrophysiological properties to those of the cloned T-type channels $\alpha 1 \mathrm{G}$ and $\alpha 1 \mathrm{H}$ and to the high voltage-activated channels formed by $\alpha 1 \mathrm{E} \beta_{3}$. The $\alpha 1$ l channels opened after small depolarizations of the membrane similar to $\alpha 1 \mathrm{G}$ and $\alpha 1 \mathrm{H}$ but at more depolarized potentials. The kinetics of activation and inactivation were dra- matically slower, which allows the channel to act as a $\mathrm{Ca}^{2+}$ injector. In oocytes, the kinetics were even slower, suggesting that components of the expression system modulate its gating properties. Steady-state inactivation occurred at higher potentials than any of the other $\mathrm{T}$ channels, endowing the channel with a substantial window current. The $\alpha 1$ l channel could still be classified as T-type by virtue of its criss-crossing kinetics, its slow deactivation (tail current), and its small (11 pS) conductance in $110 \mathrm{~mm} \mathrm{Ba}^{2+}$ solutions. Based on its brain distribution and novel gating properties, we suggest that $\alpha 11$ plays important roles in determining the electroresponsiveness of neurons, and hence, may be a novel drug target.

Key words: molecular cloning; calcium channel; CNS; thalamus; anticonvulsant; epilepsy
Voltage-gated calcium channels can be subdivided into two classes based on the voltage required to trigger channel opening. Low voltage-activated (LVA) $\mathrm{Ca}^{2+}$ channels begin to open after small depolarizations $(10 \mathrm{mV})$ of the plasma membrane, whereas high voltage-activated (HVA) channels require much stronger depolarizations $(40 \mathrm{mV})$. Most voltage-gated $\mathrm{Na}^{+}$channels open somewhere between these two extremes. Entry of $\mathrm{Ca}^{2+}$ ions causes membrane depolarization. LVA $\mathrm{Ca}^{2+}$ channels activate at potentials low enough to gate the activity of other depolarizing voltage-activated ion channels. This led to the hypothesis that LVA channels could act as pacemaker currents, controlling the activity of other voltage-gated ion channels. A clear example of this phenomenon is the thalamic low-threshold $\mathrm{Ca}^{2+}$ spike that is crowned with a burst of action potentials mediated by $\mathrm{Na}^{+}$ channels (Llinas and Jahnsen, 1982). Patch-clamp recordings demonstrated that $\mathrm{T}$-type $\mathrm{Ca}^{2+}$ channels mediated the lowthreshold spike and that they are involved in rebound burst firing, oscillations, and resonance (for review, see Huguenard, 1996).

Molecular cloning of ion channels has revealed a greater diversity than was expected from electrophysiological studies of endogenous currents. For $\mathrm{HVA} \mathrm{Ca}^{2+}$ channels, there are at least seven genes encoding $\alpha 1$ subunits, four for $\beta$, two for $\gamma$, and one for $\alpha 2$ (Bech-Hansen et al., 1998; Letts et al., 1998; Ophoff et al., 1998; Strom et al., 1998). Expression of these $\alpha 1$ subunits led to the

\footnotetext{
Received Oct. 7, 1998; revised Dec. 1, 1998; accepted Dec. 23, 1998.

This work was supported by a grant from the National Institutes of Health to E.P.-R. (HL57828). We thank Qun Jiang for technical assistance.

Correspondence should be addressed to Edward Perez-Reyes, Department of Physiology, Loyola University Medical Center, 2160 South First Avenue, Maywood, IL 60153 .

Copyright (ㄷ) 1999 Society for Neuroscience $\quad 0270-6474 / 99 / 191912-10 \$ 05.00 / 0$
}

induction of typical HVA currents in terms of their biophysical and pharmacological properties. Along with these expected properties, some HVA channels exhibited properties that were once considered specific to T-type channels. Specifically, fast inactivation, inactivation at negative membrane potentials, and block by micromolar concentrations of nickel are no longer distinguishing features (Ellinor et al., 1993; Soong et al., 1993; Zamponi et al., 1996). However, T-type currents can still be distinguished from HVA currents by the following criteria: low voltage-activation, criss-crossing pattern of currents, slow deactivation, and tiny single-channel conductance (Matteson and Armstrong, 1986; Carbone and Lux, 1987; Fox et al., 1987; Randall and Tsien, 1997).

Recently our lab has published the cloning and expression of two new $\alpha 1$ subunits, $\alpha 1 \mathrm{G}$ and $\alpha 1 \mathrm{H}$, that display all the characteristic features of T-type currents (Cribbs et al., 1998; PerezReyes et al., 1998). In this study we report the cloning of a third member of this T-type channel family, $\alpha 1 \mathrm{I}$. We compared its electrophysiological properties to those of the cloned T-type channels $\alpha 1 \mathrm{G}$ and $\alpha 1 \mathrm{H}$ and to the high voltage-activated channels formed by $\alpha 1 \mathrm{E} \beta_{3}$. Based on its brain distribution and novel gating properties, we suggest that $\alpha 1 \mathrm{I}$ plays important roles in determining the electroresponsiveness of neurons.

\section{MATERIALS AND METHODS}

$c D N A$ library screening. A rat brain $\lambda \mathrm{gt} 10$ cDNA library (catalog \#RL3005a; Clontech, Palo Alto, CA) was screened using conventional filter hybridization according to the manufacturer's protocol. All cDNA probes were released from the vector by restriction digestion, separated on agarose gels, and purified using the Qiaquick gel extraction kit (Qiagen, Valencia, CA). Probes were labeled using ${ }^{32} \mathrm{P}-\alpha$-dCTP and the 
RadPrime DNA labeling system (Life Technologies, Grand Island, NY). Probes were derived from either Integrated Molecular Analysis of Genomes and their Expression (IMAGE) Consortium (LLNL) clones (Lennon et al., 1996) (ID numbers 402278 and 50902; obtained from Genome Systems, St. Louis. MO) or PCR products. PCR primers were designed from either partial clones (IIS1f, N45) or from the genomic clone 206C7 (GenBank accession number AL008716; direct submission by J. Burgess, Wellcome Trust Genome Campus, Cambridgeshire, UK). The PCR primer sequences were as follows: IS1f, TGC ACG TGG TTT GA(AG) TG(TC) GT; IIS2r, GGC CAG CTT CAG (GAT)AT CAT (CT)TC; IIS1f, ATG GCT ATC CTG GTG AAC AC; IIIS1r, TGG GCA ATG ATG GT(CT) TG(AG) CA; IIIS1f, TTC CGG GTC CTG TG(TC) CA(AG) AC; and N45, GAT GAT GGT GGG (AG)TT GAT. The primers are named according to their approximate location in the protein and their direction ( $f$, forward; $r$, reverse). The full-length construct was assembled from five cDNA clones (Fig. $1 A$ ) in the vector pGEM-HEA (a modified version of pGEM-HE; Liman et al., 1992; gift from Kenton Swartz, National Institutes of Health, Bethesda, MD). This vector contains $5^{\prime}$ and $3^{\prime}$ untranslated regions from a Xenopus $\beta$ globin gene. Because of poor growth of bacterial cultures $\left(\mathrm{INV} \mathrm{F}^{\prime}\right.$; Invitrogen, Carlsbad, CA) transformed with this construct, we recloned the fulllength cDNA into pSP73 (Promega, Madison, WI) along with the 5' globin sequence [vector coordinates, KpnI (26)/XmaI (89)]. The same full-length cDNA was also subcloned into pcDNA3 (Invitrogen) for expression in mammalian cells. The sequence of $\alpha 1 \mathrm{I}$ was determined on both strands of the plasmid using oligonucleotide primers, Sequenase 2.0 (Amersham, Arlington Heights, IL), a digitizer, and WDNASIS software (Hitachi, San Bruno, CA). Regions of compressed sequence were resolved using the 7-deaza-GTP sequencing reaction mix (Amersham).

Northern analysis. Northern blots of $2 \mu \mathrm{g}$ of mRNA were obtained from either Origene (Rockville, MD) or Clontech. The blots were hybridized at $42^{\circ} \mathrm{C}$ for $16-20 \mathrm{hr}$ in standard solutions (Sambrook et al., 1989) containing $50 \%$ formamide. Blots were washed up to $65^{\circ} \mathrm{C}$ in a final buffer of $0.1 \times$ SSC $(15 \mathrm{~mm} \mathrm{NaCl}$ and $1.5 \mathrm{~mm} \mathrm{Na}$ citrate) and $0.1 \%$ SDS, then exposed to x-ray film (Hyperfilm MP; Amersham) at $-80^{\circ} \mathrm{C}$ between two intensifying screens. The probe was an NcoI fragment (nucleotides 5142-6197) of clone ME4, which includes the last $363 \mathrm{bp}$ of the coding region and 692 bp of $3^{\prime}$ untranslated region; none of this sequence is found in either $\alpha 1 \mathrm{G}$ or $\alpha 1 \mathrm{H}$.

Oocyte expression. Capped cRNA was synthesized from plasmid linearized with EcoRI using T7 RNA polymerase (Ambion, Austin, TX). The concentration of cRNA was measured spectrophotometrically. Oocytes were prepared from Xenopus laevis (Xenopus One, Ann Arbor, MI) using standard techniques (Leonard and Snutch, 1991). Each oocyte was injected with 2-10 ng of cRNA in a volume of $50 \mathrm{nl}$. The results were obtained from five batches of oocytes derived from five frogs.

Electrophysiological analysis of injected oocytes. Oocytes were voltageclamped using a two-microelectrode voltage-clamp amplifier (model OC725B; Warner Instrument, Hampden, CT). The standard bath solution contained the following (in $\mathrm{mm}$ ): $10 \mathrm{Ba}(\mathrm{OH})_{2}, 90 \mathrm{NaOH}, 1 \mathrm{KOH}, 0.1$ EDTA, and 5 HEPES, adjusted to $\mathrm{pH} 7.4$ with methanesulfonic acid. Voltage and current electrodes (1.5-1.8 $\mathrm{M} \Omega$ tip resistance) were filled with $3 \mathrm{M} \mathrm{KCl}$. Except where noted, data were filtered at $1 \mathrm{kHz}$ (model 902 filter; Frequency Devices, Haverhill, MA) and digitized at $4 \mathrm{kHz}$ using the pClamp system (Digidata 1200 and pClamp 6.0; Axon Instruments, Foster City, CA). In some experiments, oocytes were injected with $50 \mathrm{nl}$ of $25 \mathrm{~mm}$ BAPTA (Molecular Probes, Eugene, OR). Oocytes were allowed to recuperate for at least $1 \mathrm{hr}$ but not more than four.

For single-channel recording, the vitelline membrane was removed with forceps after shrinking in hypertonic media $\left(120 \mathrm{mM} \mathrm{K}^{+}\right.$-aspartate, $25 \mathrm{~mm} \mathrm{KCl}, 1 \mathrm{~mm} \mathrm{MgCl} 2$, $10 \mathrm{~m}$ EGTA, and $10 \mathrm{~mm}$ HEPES, pH 7.4) (Methfessel et al., 1986). Oocytes were then transferred to a depolarizing bath solution containing (in $\mathrm{mm}$ ): $120 \mathrm{~K}^{+}$-glutamate, $25 \mathrm{KCl}, 1 \mathrm{Ca}^{2+}$ ATP, 2 EGTA, 10 glucose, and 10 HEPES, pH 7.4 (Lacerda et al., 1994). Pipettes were made from 7052 glass tubing, and the tips were coated with Sylgard 184 (Dow Corning, Midland, MI). The pipette solution contained (in mM): $115 \mathrm{BaCl}_{2}, 1$ EGTA, and 10 HEPES, pH 7.4 (Lacerda et al., 1994). Single-channel currents were acquired at $10 \mathrm{kHz}$ and filtered at $2 \mathrm{kHz}$ using an Axopatch 200B, a Digidata 1200 interface, and pClamp 5 software.

Generation of stably transfected human embryonic kidney-293 cells. Human embryonic kidney-293 (HEK-293) cells $\left(1 \times 10^{6}\right.$ cells in a 100 mm culture dish) were transfected with $10 \mu \mathrm{g}$ of cDNA of either $\alpha 1 \mathrm{I}$, rat $\alpha 1 \mathrm{G}$ (Perez-Reyes et al., 1998), human $\alpha 1 \mathrm{H}$ (Cribbs et al., 1998), or human $\alpha 1 \mathrm{E}$ (Schneider et al., 1994) plus human $\beta_{3}$ (Murakami et al.,
1996; a gift from V. Flockerzi). Forty-eight hours after transfection, the cells were suspended in DMEM medium supplemented with G418 (1 $\mathrm{gm} / \mathrm{l}$, Life Technologies), 10\% fetal bovine serum, $100 \mathrm{U} / \mathrm{ml}$ penicillin, and $100 \mu \mathrm{g} / \mathrm{ml}$ streptomycin. Individual colonies were isolated with cloning rings. Results were obtained using the following cell lines: $\alpha 1 \mathrm{G}$, $\mathrm{Nr} 2+; \alpha 1 \mathrm{H}$, number 13 ; and $\alpha 1 \mathrm{E} \beta_{3}$ number $1 \mathrm{C} 5$. The results from three distinct $\alpha 1$ I-transfected cell lines (numbers 11,19 , and 25 ) were identical and have been pooled.

Electrophysiological analysis of HEK-293 transfected cells. HEK-293 cells were dissociated by digestion with $0.25 \%$ trypsin plus 1 mM EDTA (Life Technologies) for $2 \mathrm{~min}$, then diluted 20-fold with DMEM. The cells were triturated, diluted twofold with DMEM, then plated on coverslips. The cells were incubated at least $4 \mathrm{hr}$ and up to $2 \mathrm{~d}$ before electrophysiological studies. The internal pipette solution contained the following (in mM): $55 \mathrm{CsCl}, 75 \mathrm{CsSO}_{4}, 10 \mathrm{MgCl}_{2}, 0.1$ EGTA, and 10 HEPES, $\mathrm{pH}$ adjusted to 7.2 with $\mathrm{CsOH}$. The recording solution contained the following (in $\mathrm{mm}$ ): $10 \mathrm{BaCl}_{2}$ solution (or $2 \mathrm{CaCl}_{2}$ ), 140 tetraethylammonium (TEA) chloride, $6 \mathrm{CsCl}$, and 10 HEPES, $\mathrm{pH}$ adjusted to 7.4 with TEA-OH. Whole-cell currents were recorded from ruptured patches using an Axopatch 200A amplifier, Digidata 1200 analog-to-digital converter, and pClamp 6.0 software (Axon Instruments). Data were filtered at $1 \mathrm{kHz}$ and digitized at $2 \mathrm{kHz}$, except for measurement of tail currents that were digitized at $50 \mathrm{kHz}$. Pipettes were made of TW-150-6 capillary tubing, using a model P-97 Flaming-Brown pipette puller (Sutter Instruments, Novato, CA). Under these solution conditions, the pipette resistance was typically $1.5-2.0 \mathrm{M} \Omega$. Series resistance (correction and prediction) and cell capacitance were compensated $\sim 80 \%$. The average cell capacitance was $\sim 25 \mathrm{pF}$. The data were not corrected for any residual leak currents. All experiments were performed at room temperature.

Data analysis. Peak currents, integrals, and exponential fits to the electrophysiological data were determined using Clampfit software (Axon Instruments). Conductance was calculated using the GoldmanHodgkin-Katz equation (Hille, 1992) and the solver function of Excel (Microsoft). Capacitative transients were removed from single-channel records by subtracting null sweeps taken from the same experiment and were then analyzed using Transit (VanDongen, 1996). Single-channel amplitudes were measured by averaging the values obtained from both Gaussian fits to all-points histograms of traces with openings and amplitude histograms of all idealized openings. Fits and graphing of the data were with Prism (GraphPad, San Diego, CA).

\section{RESULTS}

Cloning of T-type $\mathrm{Ca}^{2+}$ channels began with the identification of an EST clone [IMAGE Consortium (Lennon et al., 1996) clone ID number 44039] as being derived from a novel channel (PerezReyes et al., 1998). Homology analysis of the full sequence of this clone (GenBank accession number AF02922) identified a Caenorhabditis elegans homolog (GenBank accession number 1017809). The amino acid sequence corresponding to the sixth membranespanning region of repeat IV (IVS6) was used to search the EST database using the BLAST algorithm (Altschul et al., 1990), leading to the identification of IMAGE Consortium clones number 50902 (GenBank accession number H19230) and number 402278 (GenBank accession number W76774). Subsequent cloning of the full-length cDNAs for $\alpha 1 \mathrm{G}$ and $\alpha 1 \mathrm{H}$ and mapping of their chromosomal location allowed us to identify these clones as being derived from two genes, $C A C N A 1 G$ and $C A C N A 1 H$ (Cribbs et al., 1998; Perez-Reyes et al., 1998).

A rat brain cDNA library was screened at low stringency with H19230 $(\alpha 1 \mathrm{G})$, leading to the isolation of fifty positive plaques. Many of these plaques were not detected in the secondary screening. To test if these lost plaques were derived from $\alpha 1 \mathrm{H}$, they were rescreened with W76774. Two recombinants were detected with this probe and plaque-purified (clones ME4 and ME5). Sequencing of their cDNA inserts demonstrated that they were similar to each other but clearly different from either $\alpha 1 \mathrm{G}$ or $\alpha 1 \mathrm{H}$, hence, we called it $\alpha 1 \mathrm{I}$ or $\mathrm{Ca}_{\mathrm{v}}$ T.3. This conclusion was supported by having a representative member of each gene cloned from the 
A

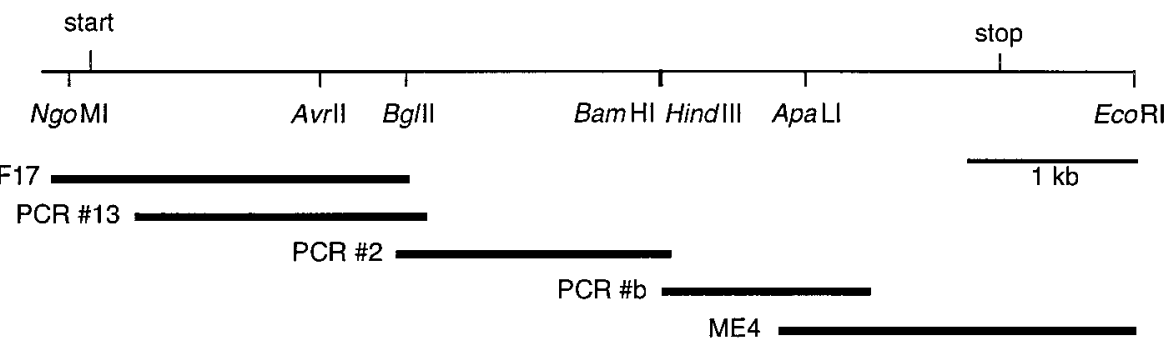

Figure 1. Primary structure and predicted topology of the rat $\alpha 1 \mathrm{I}\left(\mathrm{Ca}_{\mathrm{v}} \mathrm{T} .3\right)$. $A$, Schematic showing the location of the restriction enzyme sites and clones used for constructing the full-length cDNA. The cDNA construct was assembled from the following clones: $\lambda \mathrm{gt10}$ clone RF17, NgoM1 (-124)/AvrII (1354); PCR clone number 13, AvrII (1354)/BglII (1893); PCR clone number 2, BglII (1893)/BamHI (3357); a synthetic pair of oligonucleotides, BamHI (3357)/HindIII(3386); PCR clone b, HindIII(3386)/ApaLI (4327); and $\lambda$ gt10 clone ME4, ApaLI (4327)/EcoRI (polylinker). $B$, Deduced amino acid sequence of the rat $\alpha 1 \mathrm{I}$ T-type calcium channel. Residues conserved among the rat $\alpha 1 \mathrm{I}$, rat $\alpha 1 \mathrm{G}$, and the human $\alpha 1 \mathrm{H}$ are shown in capitalized bold letters. Putative membrane-spanning regions are marked above the sequence. Analysis of the $\alpha 1 \mathrm{I}$ protein sequence with a modified Prosite database identified the following: four cAMP-dependent protein kinase phosphorylation motifs $(\mathrm{R} / \mathrm{K}-\mathrm{R} / \mathrm{K}-\mathrm{x}-\mathrm{S} / \mathrm{T}$ or $\mathrm{R} / \mathrm{K}-\mathrm{R} / \mathrm{K}-\mathrm{x}-\mathrm{x}-\mathrm{S} / \mathrm{T}$ ) all located in the intracellular loops (marked above site with the letter $a$ ); 18 protein kinase $\mathrm{C}$ motifs ( $\mathrm{S} / \mathrm{T}$ $x-R / K)$, eight of which are located intracellularly (marked with $c$ ); one tyrosine phosphorylation motif $(\mathrm{R} / \mathrm{K}-\mathrm{x}-\mathrm{x}-\mathrm{x}-\mathrm{D}-\mathrm{x}-$ $\mathrm{x}-\mathrm{Y}$ ) located at the start of IIS1 (marked with $y$ ), and seven N-linked glycosylation motifs $(\mathrm{N}-\mathrm{x}-\mathrm{S} / \mathrm{T})$, five of which are in extracellular loops (marked with $n$ ). $C$, Schematic of the $\alpha 1$ I channel showing relationship of loops to the plasma membrane. Each amino acid residue is represented by a circle. For diagrammatic purposes, the membrane-spanning regions are modeled as $\alpha$ helices.
B

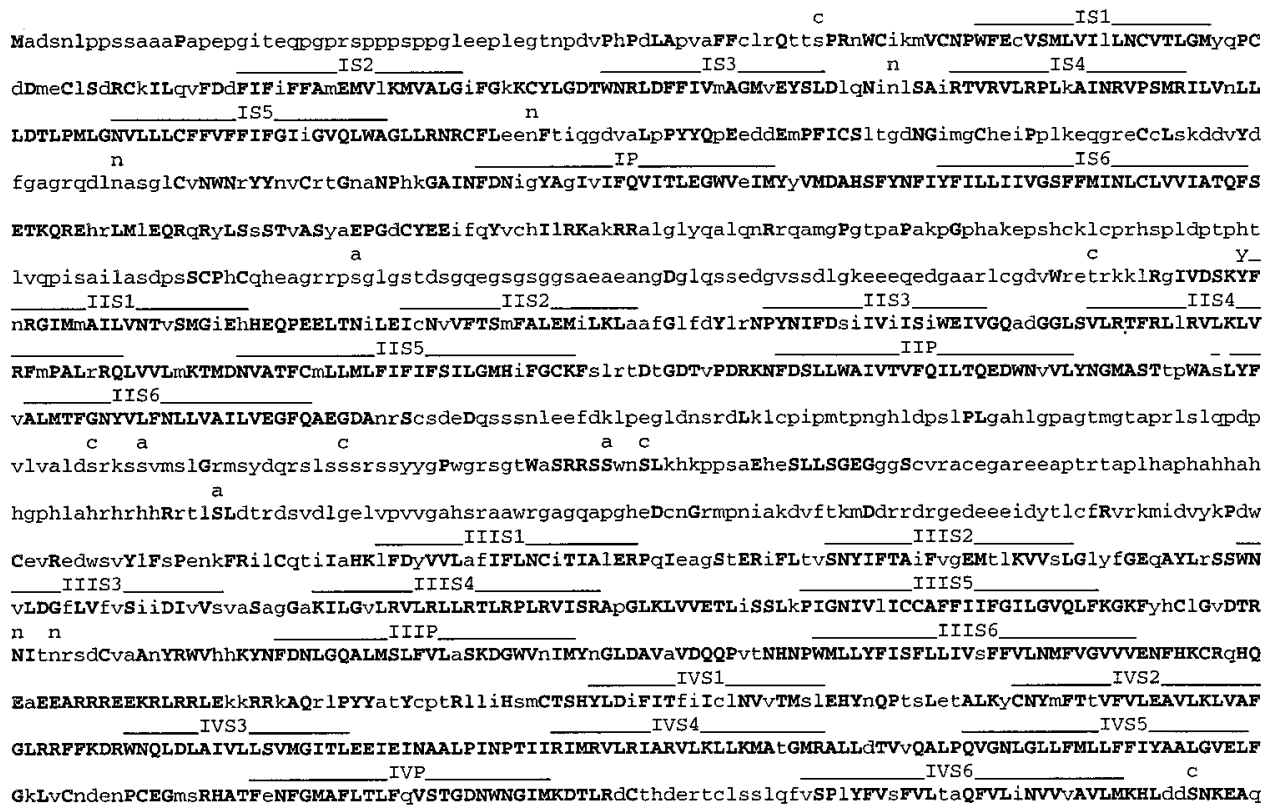
EdAEndAEiELEMahglgpcpgpcpgpcpcpcpcpcagprlptsspgapgrgsggagaggdteshlcrhcyspaget lwldsvsli ikdslegelti idn lsgsvfhhyaspdgcgkchhdkgetglhpscwgmt

1835

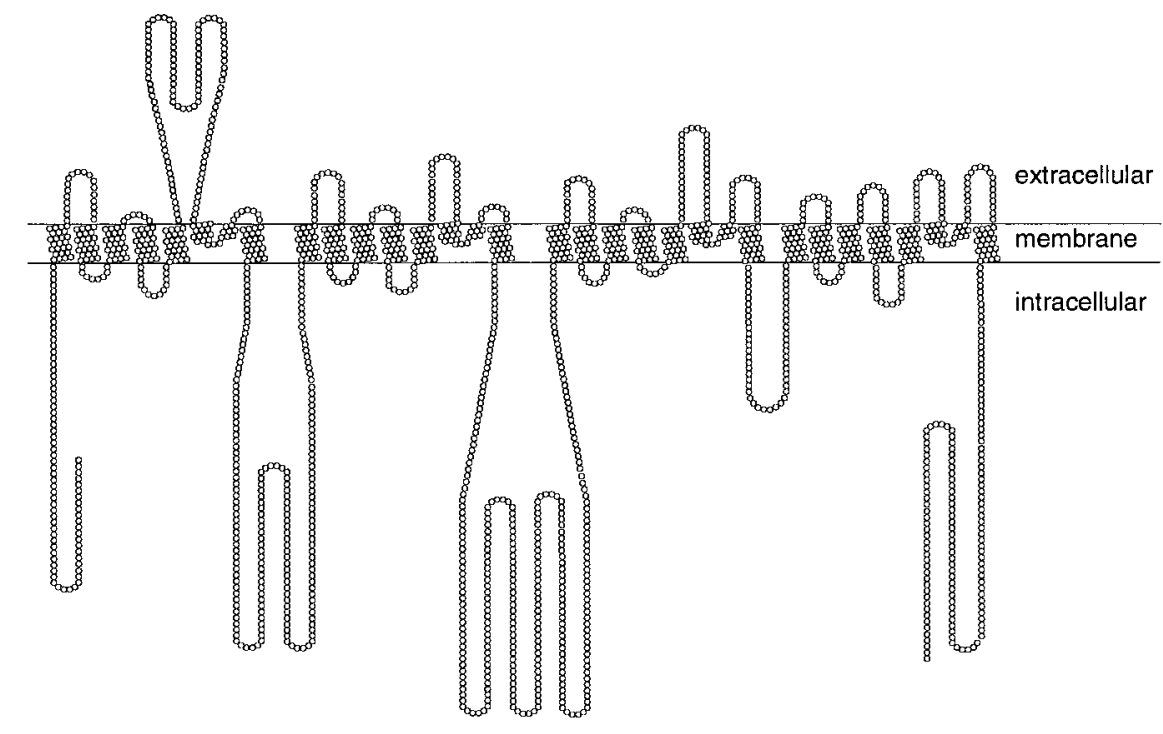


rat brain library (UN7, $\alpha 1 \mathrm{G}$; ME3, $\alpha 1 \mathrm{H}$; and ME4, $\alpha 1 \mathrm{I})$. A subsequent search of the HTGS division of the GenBank with the full-length $\alpha 1 \mathrm{G}$ sequence (AF027984) allowed us to recognize the human genomic sequence of $\alpha 1 \mathrm{I}$ (and refer to the gene as $C A C N A 1 I$ ) on cosmid 20CC7 derived from chromosome 22. This sequence was used to design three sets of PCR primers to clone the cDNA encoding repeats I-III.

The PCR product containing repeat I was used to isolate the 5' end from the rat brain $\lambda$ gt10 cDNA library. Four clones were isolated, but only RF17 extended into the presumptive 5' untranslated region. Although clone RF17 contains 278 base pairs at the $5^{\prime}$ end that are enriched with the nucleotides $\mathrm{G}$ and $\mathrm{C}(80 \%$ compared with $58 \%$ for the coding region), it does not contain an in-frame stop codon. Additional support for our assignment of the start codon comes from the sequence of human cosmid clone 1104E15 (direct submission by J. Sulton, Wellcome Trust Genome Campus). This clone contains a presumptive exon encoding 79 amino acids that are $83 \%$ identical to the rat sequence, spanning from the amino terminus sequence to IS1. An in-frame stop codon occurs $171 \mathrm{bp}$ before the start codon we predicted from the rat sequence.

The full-length rat $\alpha 1 \mathrm{I}$ cDNA is composed of 6503 bp (GenBank accession number AF086827). The open reading frame covers $5505 \mathrm{bp}$, encoding a protein with a predicted molecular weight of 205,198 (Fig. $1 B$ ). The $\alpha 1$ I protein is $59.3 \%$ identical to human $\alpha 1 \mathrm{H}$ and $56.9 \%$ identical to rat $\alpha 1 \mathrm{G}$. In contrast, it is only $13-19 \%$ identical to the HVA $\alpha 1$ subunits. Most of the residues conserved in all three $\mathrm{T}$ channel proteins (Fig. 1B) and in HVA $\alpha 1$ subunits are found in the putative membrane-spanning regions. These membrane-spanning regions also share considerable structural homology to voltage-gated $\mathrm{K}^{+}$and $\mathrm{Na}^{+}$channels (Jan and Jan, 1990), suggesting that the overall topology (Fig. 1C) of these channels is similar (Durell et al., 1998). The intracellular loops connecting each repeat and the $\mathrm{C}$ terminus are poorly conserved. The T channel $\alpha 1$ proteins contain stretches of histidine and arginine residues, as noted previously for high voltageactivated $\alpha 1$ subunits (Perez-Reyes and Schneider, 1994). In $\alpha 1 \mathrm{G}$ and $\alpha 1 \mathrm{H}$, this motif occurs in the I-II linker, whereas in $\alpha 1 \mathrm{I}$ it occurs in the II-III linker. In contrast to HVA $\alpha 1$ subunits, the three LVA channels contain a large (107 residues) extracellular loop located between IS5 and the P loop. All other extracellular loops are predicted to be smaller $(<35)$. Although the amino acid sequence is not highly conserved $(45 \%)$, there are six conserved cysteine residues. Because disulfide bonds are formed in extracellular domains of proteins, this loop may play a role in localizing channels to the cell surface. The $\mathrm{C}$ terminus is composed of only 143 amino acids, which is similar in length to human $\alpha 1 \mathrm{H}$ (185), but shorter than either rat $\alpha 1 \mathrm{G}$ (430) or HVA channels such as human $\alpha 1 \mathrm{C}$ (773) or $\alpha 1 \mathrm{E}$ (590). It also contains nine sequential copies of the repeat, TGCCCC, leading to runs of prolines and cysteines. This repetitive element is not found in the human genomic sequence. Analysis of the $\alpha 1$ I protein sequence with a modified Prosite database identified the following: four cAMP-dependent protein kinase phosphorylation motifs located in the intracellular loops (Fig. $1 B$ ), eight protein kinase $\mathrm{C}$ motifs located intracellularly, one tyrosine phosphorylation motif located at the start of IIS1, and five N-linked glycosylation motifs on extracellular loops. Motifs for binding $\beta$ subunits of either G-proteins (Q-X-X-E-R; Chen et al., 1995) or HVA calcium channels (Q-Q-X-E-X-X-L-X-G-Y-X-X-W-I-X-X-X-E; DeWaard et al., 1996) were not identified.

The distribution of $\alpha 1 \mathrm{I}$ mRNA in various rat tissues was

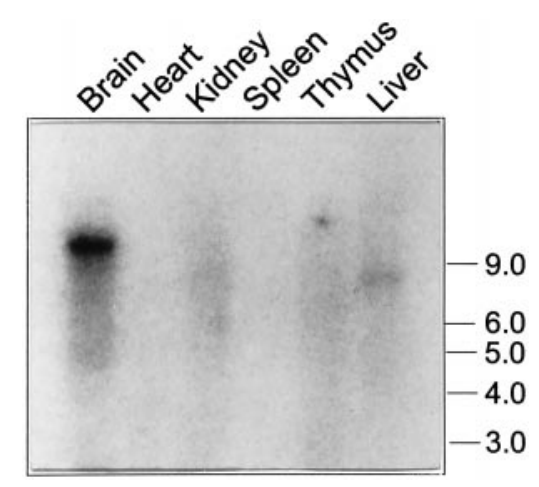

Figure 2. Distribution of $\alpha 1 \mathrm{I}$ mRNA by Northern blot analysis. A rat multiple-tissue blot was probed with ${ }^{32} \mathrm{P}$-labeled $\alpha 1 \mathrm{I}$ (nucleotides 5142 6197) and exposed for $5 \mathrm{~d}$. Size markers are indicated on the right in kilobases. The faint $8 \mathrm{~kb}$ bands in kidney and liver were only observed in one experiment and may be caused by contamination of the probe with sequence encoding repeat IV leading to cross-hybridization with $\alpha 1 \mathrm{H}$ (Cribbs et al., 1998). Alternatively, these bands may represent crosshybridization with a distinct mRNA.

determined by Northern blot analysis (Fig. 2). The predominant species detected had a mobility corresponding to $10.5 \mathrm{~kb}$ and was only found in brain. Similar results were obtained with two other blots. Minor bands were also observed at 2 and $8 \mathrm{~kb}$. The intensity of the $2 \mathrm{~kb}$ band varied between experiments and showed a wider tissue distribution.

Functional expression of $\alpha 1 \mathrm{I}$ currents was first studied in $\mathrm{Xe}$ nopus oocytes injected with cRNA. Quite surprisingly, the currents activated very slowly, particularly at threshold voltages where the time-to-peak was $>150 \mathrm{msec}$ (Fig. $3 A, B$ ). Robust expression $(>1 \mu \mathrm{A})$ was obtained in most batches of oocytes. Oocytes expressing $>2 \mu \mathrm{A}$ were excluded from the analysis, which reduced the average peak current to $-718 \pm 146 \mathrm{nA}$. Kinetics were not affected by BAPTA injection into the oocytes before recording $(n=5)$, so the data were pooled. This result indicated that there was minimal activation of the $\mathrm{Ca}^{2+}$-activated $\mathrm{Cl}$ current. To investigate the possibility of a mutation, the full-length cDNA construct was sequenced. No striking differences were observed in the sequence of $\alpha 1 \mathrm{I}$ as compared with either the human genomic sequences containing CACNA1I, (GenBank accession numbers AL022319, AL008716), rat $\alpha 1 \mathrm{G}$ (GenBank accession number AF027984), or human $\alpha 1 \mathrm{H}$ (GenBank accession number AF051946).

When $\alpha 1$ I was expressed by stable transfection into HEK-293 cells, the currents were twofold faster ( $80 \mathrm{msec}$ time-to-peak at threshold; Fig. $3 A, C$ ) than observed in oocytes, but their kinetics were much slower than observed previously for either $\alpha 1 \mathrm{G}$ (Perez-Reyes et al., 1998) or $\alpha 1 \mathrm{H}$ (Cribbs et al., 1998). To compare the gating properties of cloned voltage-gated $\mathrm{Ca}^{2+}$ channels, we prepared stably transfected HEK-293 cells of $\alpha 1 \mathrm{I}, \alpha 1 \mathrm{G}, \alpha 1 \mathrm{H}$, and $\alpha 1 \mathrm{E}$ plus $\beta_{3}$. Robust expression ( $>1 \mathrm{nA}$; Fig. $4 A$ ) was obtained with all cloned channels. Representative current traces obtained during pulses of varying test potentials are shown in Figure $3 C-F$. The peak currents were averaged and plotted versus test potential (Fig. 4A). To illustrate the position of these current-voltage curves, the data from each cell were normalized to the largest peak current observed, then averaged (Fig. 4B). These results indicated that $\alpha 1 \mathrm{I}, \alpha 1 \mathrm{G}$, and $\alpha 1 \mathrm{H}$ channels were all activated at low voltages. In contrast, $\alpha 1 \mathrm{E} \beta_{3}$ channels required stronger depolarizations $(30 \mathrm{mV})$ to open. To quantitate these differences, conductance was calculated using the Goldman- 
A
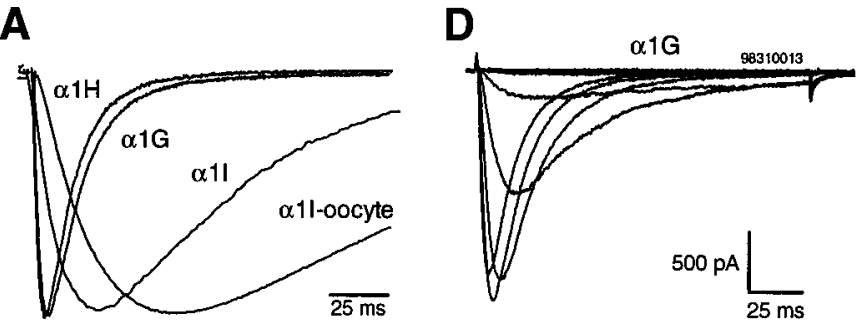

B

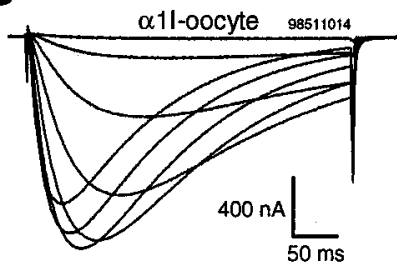

C

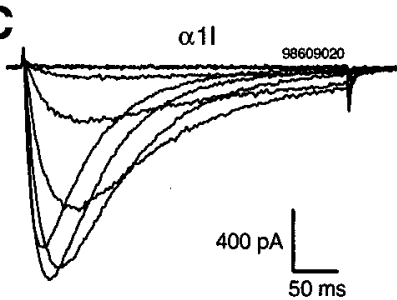

E

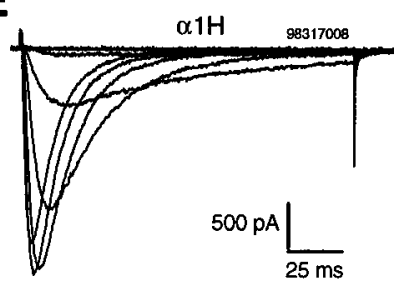

$\mathbf{F}$

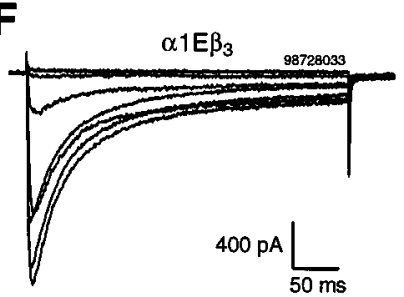

Figure 3. Comparison of the $\alpha 1 \mathrm{I}$ currents to cloned $\alpha 1 \mathrm{G}, \alpha 1 \mathrm{H}$, and $\alpha 1 \mathrm{E} \beta_{3}$ channel currents. Currents were evoked by step depolarizations to varying test potentials from a holding potential of $-90 \mathrm{mV}$. Currents were measured in stably transfected HEK-293 cells using the ruptured patchclamp method with $10 \mathrm{mM} \mathrm{Ba}^{2+}$ as the charge carrier. Also shown are results from Xenopus oocytes expressing $\alpha 1 \mathrm{I}$. $A, \alpha 1 \mathrm{I}$ currents expressed in HEK-293 cells and Xenopus oocytes were compared with $\alpha 1 \mathrm{G}$ and $\alpha 1 \mathrm{H}$ currents expressed in HEK-293 cells. Currents from the peak of the current-voltage relationship have been scaled and superimposed. Data were taken from the same cells shown in panels $B-F$. $B$, Representative current traces recorded from oocytes injected with $\alpha 1$ I-cRNA. Currents were evoked during test pulses that incremented $7 \mathrm{mV}$ with each episode. $C-F$, Representative currents from HEK-293 cells stably transfected with either $\alpha 1 \mathrm{I}(C), \alpha 1 \mathrm{G}(D), \alpha 1 \mathrm{H}(E)$, or $\alpha 1 \mathrm{E} \beta_{3}(F)$. Currents were elicited by depolarizing $10 \mathrm{mV}$ steps from $-90 \mathrm{mV}$.

Hodgkin-Katz equation and fit with the Boltzmann equation (see Fig. 6C). The values of half-maximal activation $\left(\mathrm{V}_{0.5}\right)$ and slope $(k)$ are presented in Table 1 . These results show that each cloned T-type channel activated at slightly different potentials, with $\alpha 1 \mathrm{H}$ being the most negative followed closely by $\alpha 1 \mathrm{G}$, whereas $\alpha 1 \mathrm{I}$ activated at $7 \mathrm{mV}$ higher test potentials. In contrast, $\alpha 1 \mathrm{E} \beta_{3}$ currents activated $15 \mathrm{mV}$ more positive than $\alpha 1 \mathrm{I}$. These results were obtained using $10 \mathrm{mM} \mathrm{Ba}^{2+}$ as the charge carrier. Because of the effects on surface charge screening by such high concentrations of divalent cation (Wilson et al., 1983), we also measured currents under more physiological conditions $(2 \mathrm{~mm}$ $\mathrm{Ca}^{2+}$; Table 1). The currents through $\alpha 1 \mathrm{I}, \alpha 1 \mathrm{G}$, and $\alpha 1 \mathrm{H}$ channels also had an apparent reversal potential that was $\sim 15 \mathrm{mV}$ more negative than $\alpha 1 \mathrm{E} \beta_{3}$ (Fig. $4 B$ ). Integrated currents from representative cells, each of which had $\sim 1 \mathrm{nA}$ of peak current, were also plotted as a function of the test potential (Fig. 4C). These results showed that $\alpha 1$ I caused the biggest influx of $\mathrm{Ba}^{2+}$ among the cloned channels.

To measure both activation and inactivation time courses, the pulse was lengthened to $350 \mathrm{msec}$, and the resulting data were fit
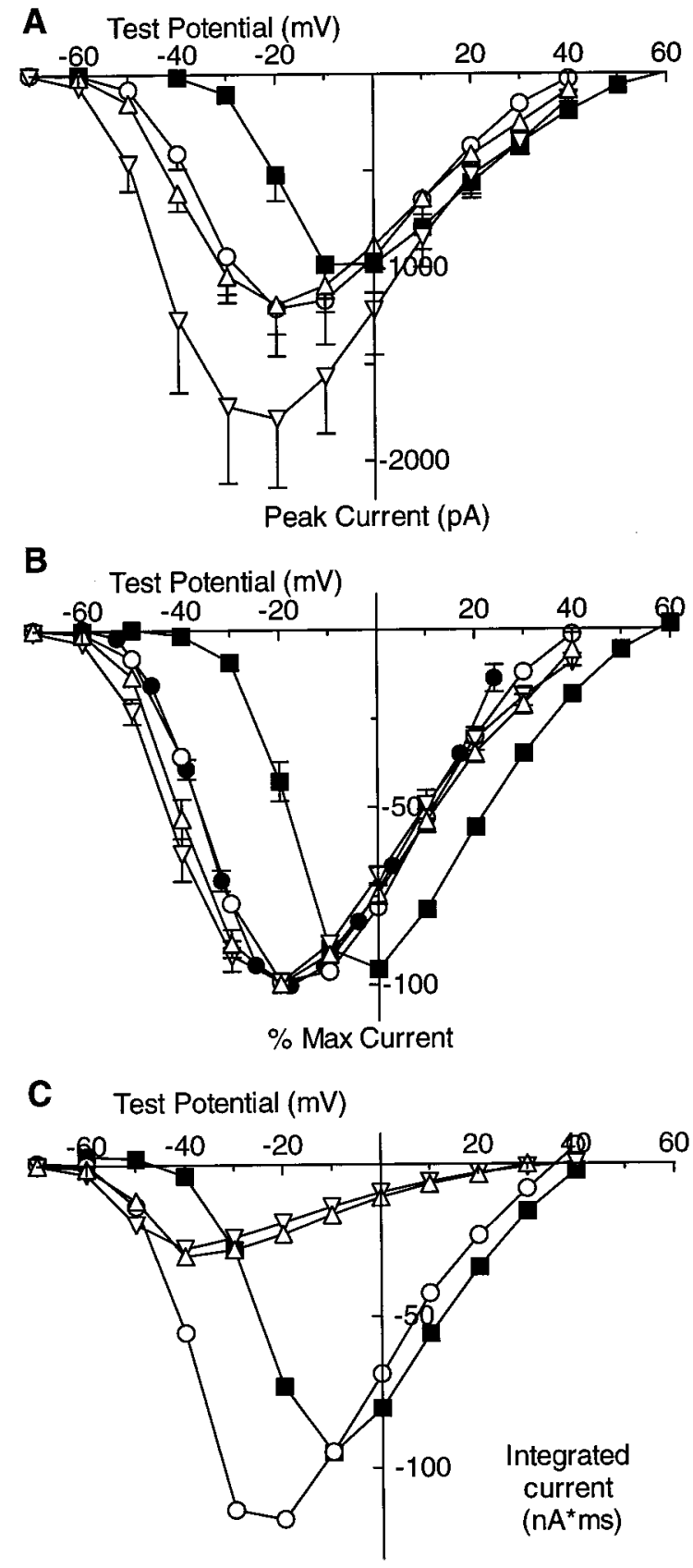

Figure 4. Comparison of the current-voltage $(I-V)$ relationships of $\alpha 1 \mathrm{I}$ to those of $\alpha 1 \mathrm{G}, \alpha 1 \mathrm{H}$, and $\alpha 1 \mathrm{E} \beta 3$. Symbols representing each cloned channel are the same in Figures 4-6: $\alpha 1 \mathrm{G}(\triangle), \alpha 1 \mathrm{H}(\nabla), \alpha 1 \mathrm{I}(\bigcirc)$, and $\alpha 1 \mathrm{E} \beta_{3}(\square)$. $A$, Average peak currents elicited during test pulses to the indicated potentials. Data represent the mean \pm SEM from the following number of cells: $\alpha 1 \mathrm{G}(n=8), \alpha 1 \mathrm{H}(n=6), \alpha 1 \mathrm{I}(n=10)$, and $\alpha 1 \mathrm{E} \beta_{3}(n=$ 10). $B$, The data in $A$ were normalized to the peak current observed for each cell then averaged. Also shown is the average data obtained with oocytes injected with $\alpha 1 \mathrm{I}(\boldsymbol{\bullet} ; n=12)$. $C$, Integral of the current measured during each test pulse is plotted as a function of test potential. Representative cells were chosen that each expressed $1 \mathrm{nA}$ current at the peak of the $I-V$.

with two exponentials (Fig. 5A,B). As observed for both native (Huguenard, 1996) and cloned T-type channels (Cribbs et al., 1998; Perez-Reyes et al., 1998), activation and inactivation kinetics were slow near threshold voltages and accelerated with increasing depolarizations, producing a classical criss-crossing pat- 
Table 1. Summary of the voltage-dependent properties of cloned calcium channels

\begin{tabular}{|c|c|c|c|c|c|c|}
\hline & \multicolumn{3}{|l|}{ Activation } & \multicolumn{3}{|l|}{ Inactivation } \\
\hline & $\mathrm{V}_{50}$ & $\mathrm{k}$ & $\tau_{\text {act }}$ & $\mathrm{V}_{50}$ & $\mathrm{k}$ & $\tau_{\text {in }}$ \\
\hline$\alpha 1 \mathrm{I}$ & $-24.7 \pm 0.2$ & $8.1 \pm 0.2$ & $4.7 \pm 0.3$ & $-68.3 \pm 0.8$ & $-6.3 \pm 0.7$ & $55 \pm 3$ \\
\hline$\alpha 1 \mathrm{G}$ & $-28.6 \pm 0.9$ & $8.9 \pm 0.8$ & $1.8 \pm 0.1$ & $-72.4 \pm 0.5$ & $-4.8 \pm 0.5$ & $15 \pm 1$ \\
\hline$\alpha 1 \mathrm{H}$ & $-31.4 \pm 0.9$ & $8.8 \pm 0.8$ & $1.7 \pm 0.2$ & $-80.9 \pm 0.4$ & $-5.5 \pm 0.4$ & $14 \pm 1$ \\
\hline$\alpha 1 \mathrm{E} \beta 3$ & $-10.9 \pm 0.5$ & $6.3 \pm 0.4$ & $1.3 \pm 0.1$ & $-75.5 \pm 0.5$ & $-7.3 \pm 0.5$ & $48 \pm 2$ \\
\hline$\alpha 1 \mathrm{I}-2 \mathrm{Ca}$ & $-45.0 \pm 0.9$ & $7.6 \pm 0.8$ & $3.9 \pm 0.3$ & $-77.1 \pm 0.6$ & $-6.0 \pm 0.5$ & $76 \pm 10$ \\
\hline
\end{tabular}

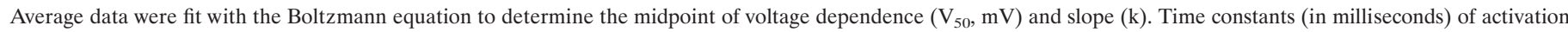
and inactivation were calculated from double exponential fits to the current traces obtained during test pulses to $+10 \mathrm{mV}$.
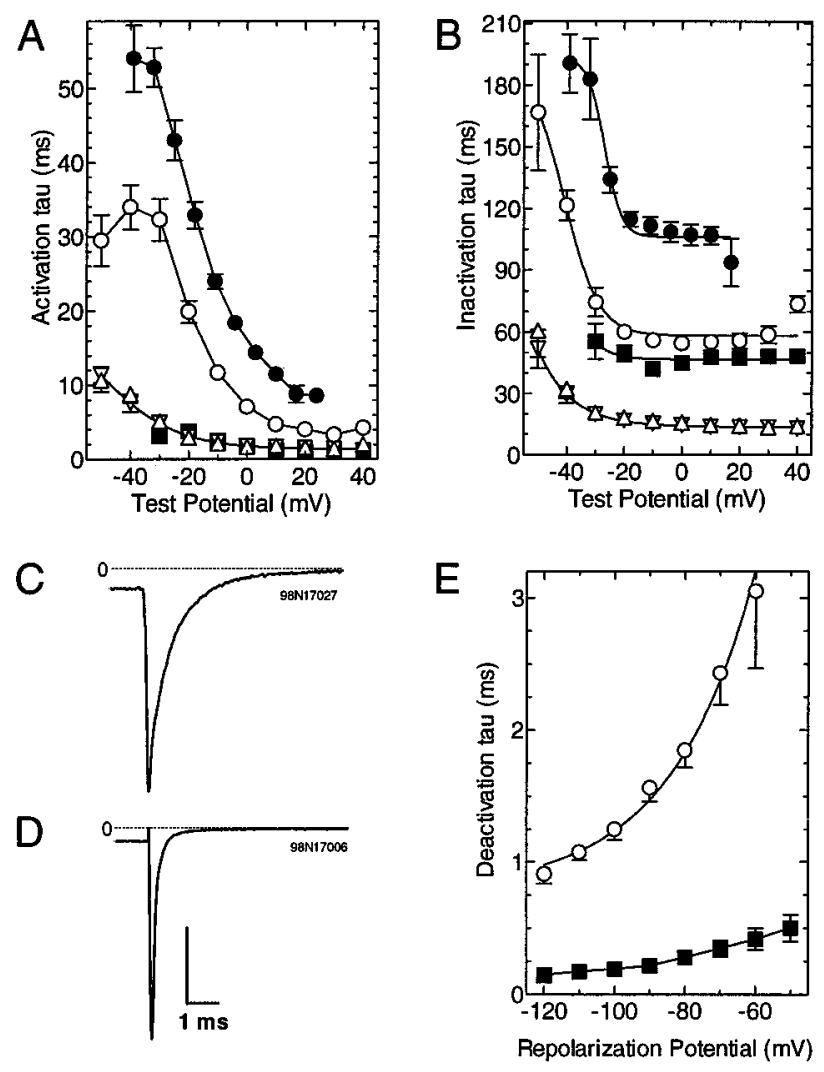

Figure 5. Comparison of the kinetic properties of $\alpha 1 \mathrm{I}$ with those of $\alpha 1 \mathrm{G}$, $\alpha 1 \mathrm{H}, \alpha 1 \mathrm{I}$, and $\alpha 1 \mathrm{E} \beta_{3} . A, B$, Currents elicited during the $I-V$ protocol were fit with two exponentials. Average activation $(A)$ and inactivation $(B)$ tau values are plotted as a function of test potential. All currents were recorded from HEK-293 cells, except for the data represented by $\boldsymbol{Q}$, which are from oocytes injected with $\alpha 1 \mathrm{I}$. Data represent the mean \pm SEM from the following number of cells: $\alpha 1 \mathrm{G}(\triangle, n=8), \alpha 1 \mathrm{H}(\nabla, n=6), \alpha 1 \mathrm{I}(\bigcirc$, $n=10), \alpha 1 \mathrm{I}$ in oocytes $(\bullet, n=15)$, and $\alpha 1 \mathrm{E} \beta_{3}(\boldsymbol{\square}, n=14) . C, D$, Representative tail currents from cells expressing either $\alpha 1 \mathrm{I}(C)$ or $\alpha 1 \mathrm{E} \beta_{3}$ $(D)$. Currents were evoked by test pulses to either $-20(\alpha 1 \mathrm{I})$ or $0\left(\alpha 1 \mathrm{E} \beta_{3}\right)$ $\mathrm{mV}$, followed by repolarization to $-100 \mathrm{mV}$. Vertical scale bar represents $1(C)$ or $5 \mathrm{nA}(D) . E$, Data obtained in $C$ and $D$ were fit with a single exponential. Average deactivation time constants of $\alpha 1 \mathrm{I}(n=4)$ and $\alpha 1 \mathrm{E} \beta_{3}(n=4)$ tail currents were plotted as a function of repolarization potential.

tern (Randall and Tsien, 1997). This pattern was clearly distinct from HVA channels such as $\alpha 1 \mathrm{E} \beta_{3}$ (Fig. $3 F$ ) whose activation and inactivation time constants were relatively voltageindependent (Fig. 5A,B). The current kinetics of $\alpha 1 \mathrm{G}$ and $\alpha 1 \mathrm{H}$ were voltage-dependent and were nearly identical to each other. Similar results were obtained previously with $\alpha 1 \mathrm{G}$ expressed in oocytes (Perez-Reyes et al., 1998) and $\alpha 1 \mathrm{H}$ in transiently transfected HEK-293 cells (Cribbs et al., 1998). In contrast, $\alpha 1$ I kinetics were threefold slower in HEK-293 cells and sixfold slower in oocytes.

A second defining feature of T-type $\mathrm{Ca}^{2+}$ currents is that they deactivate relatively slowly, producing slowly decaying tail currents after a depolarizing pulse. Representative tail currents for $\alpha 1 \mathrm{I}$ and $\alpha 1 \mathrm{E} \beta_{3}$ are shown in Figure 5, $C$ and $D$, respectively. The data were fit with a single exponential to determine the time constant for deactivation (Fig. $5 E$ ). These results indicated that $\alpha 1 \mathrm{I}$ channels closed at least sixfold slower than $\alpha 1 \mathrm{E} \beta 3$ channels (at $-100 \mathrm{mV}, \alpha 1 \mathrm{I} \tau, 1.25 \pm 0.08 \mathrm{msec} ; \alpha 1 \mathrm{E} \beta 3,0.19 \pm 0.03 \mathrm{msec}$; $n=4$ for both). Fast deactivating tail currents have also been reported previously for both $\alpha 1 \mathrm{E} \alpha_{2} \beta_{1 \mathrm{a}}$ and R-type currents (Williams et al., 1994; Randall and Tsien, 1997).

Inactivation was also studied by applying 5-sec-long prepulses that were terminated by a brief $(5 \mathrm{msec})$ repolarization to close any open channels, then followed by a test pulse to $-30 \mathrm{mV}$ to measure channel availability. Representative current traces recorded during prepulses to -50 and $-55 \mathrm{mV}$ are shown in Figure $6 A$. Average data were fit with the Boltzmann equation (Fig. $6 B$, Table 1). These results showed that each cloned T-type channel inactivated at slightly different potentials, with $\alpha 1 \mathrm{H}$ inactivating at the lowest potentials, followed by $\alpha 1 \mathrm{G}$, whereas $\alpha 1 \mathrm{I}$ required potentials that were $15 \mathrm{mV}$ higher. Comparison of $\alpha 1 \mathrm{I}$ channels in HEK-293 cells to those expressed in oocytes indicated that the voltage dependence of activation was nearly identical (Fig. 4B) but that inactivation occurred at $7 \mathrm{mV}$ higher potentials in oocytes $\left(\mathrm{V}_{50}=-57.7 \pm 0.8 ; n=7\right)$. In contrast, the voltage dependence of $\alpha 1 \mathrm{G}$ was nearly identical in HEK-293 cells, as reported previously for oocytes (Perez-Reyes et al., 1998). The traces in Figure $6 A$ were chosen to illustrate that there are voltages at which channels were activated during the prepulse, but they were not completely inactivated, as evidenced by currents evoked during the test pulse. This activity is referred to as a window current and is typically illustrated by the overlap in the steady-state inactivation and activation curves. The resulting window regions for $\alpha 1 \mathrm{I}, \alpha 1 \mathrm{G}, \alpha 1 \mathrm{H}$, and $\alpha 1 \mathrm{E} \beta_{3}$ are shown in panels $D-I$ of Figure 6 . Of the three T-type channels, $\alpha 1 \mathrm{I}$ had the largest window region. In contrast, $\alpha 1 \mathrm{E} \beta_{3}$ currents did not display a significant window region because inactivation occurred at very negative potentials. The window region is also shown for $\alpha 1 \mathrm{I}$ currents measured with $2 \mathrm{~mm} \mathrm{Ca}^{2+}$ (Fig. 6I). At the peak of the window $(-64 \mathrm{mV}), \sim 0.6 \%$ of the $\alpha 1 \mathrm{I}$ channels may open (percentage of channels available to gate times the number of channels that gate at that potential).

T-type channels are also defined by their tiny single-channel conductance in saturating concentrations of $\mathrm{Ba}^{2+}$ (Fox et al., 1987; Huguenard, 1996). To measure these small currents, we 
A

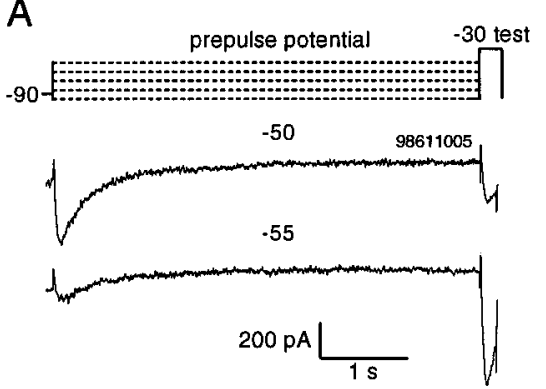

B
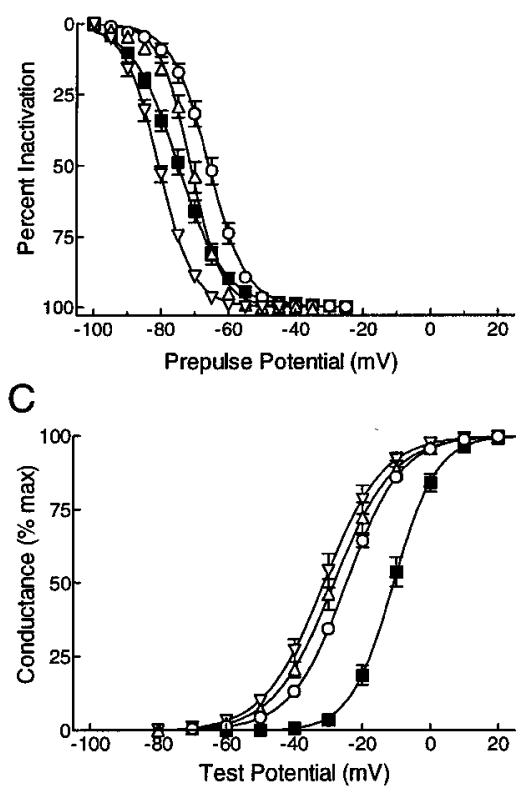

D
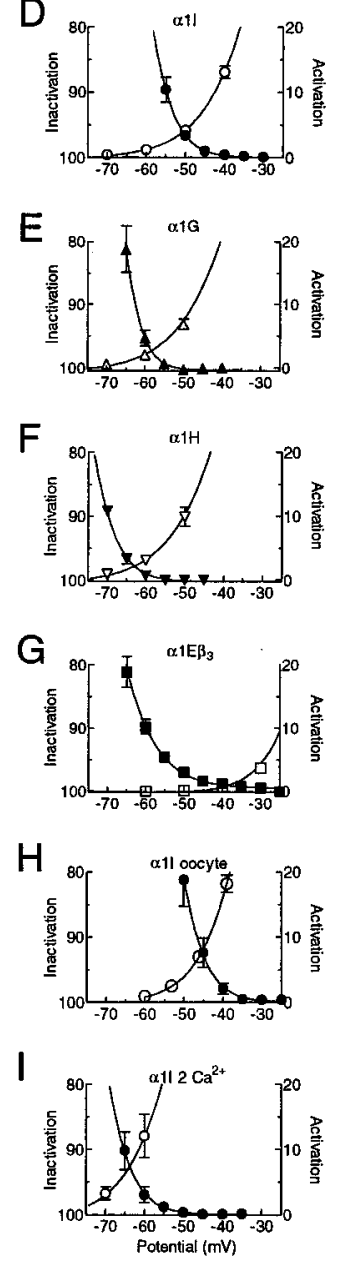

Figure 6. Comparison of steady-state inactivation, activation, and window currents of $\alpha 1 \mathrm{I}$ to those of $\alpha 1 \mathrm{G}, \alpha 1 \mathrm{H}$, and $\alpha 1 \mathrm{E} \beta_{3}$. A, The voltage protocol used to measure inactivation is shown above representative traces obtained during prepulses to -50 and $-55 \mathrm{mV}$. The protocol also included a short $5 \mathrm{msec}$ repolarization to $-90 \mathrm{mV}$ at the end of the prepulse. The time between episodes was $15 \mathrm{sec}$. $B$, Average percent inactivation was plotted as a function of prepulse voltage. The average data were fit with the Boltzmann equation (smooth curves). Data represent the mean \pm SEM from the following number of observations: $\alpha 1 \mathrm{G}$ $(\triangle, n=6), \alpha 1 \mathrm{H}(\nabla, n=8), \alpha 1 \mathrm{I}(\bigcirc, n=7)$, and $\alpha 1 \mathrm{E} \beta_{3}(\mathbf{\square}, n=12) . C$, Conductance was calculated using the Goldman-Hodgkin-Katz equation. The data were averaged, then fit with the Boltzmann equation (smooth curves). Data represent the mean \pm SEM from the following number of observations: $\alpha 1 \mathrm{G}(n=8), \alpha 1 \mathrm{H}(n=6), \alpha 1 \mathrm{I}(n=8)$, and $\alpha 1 \mathrm{E} \beta_{3}(n=14) . D-I$, Activation and inactivation curves shown in $B$ and $C$ were overlapped and expanded to show window currents. Data for $\alpha 1 \mathrm{I}$ $(D), \alpha 1 \mathrm{G}(E), \alpha 1 \mathrm{H}(F), \alpha 1 \mathrm{E} \beta_{3}(G)$, and $\alpha 1 \mathrm{I}$ expressed in oocytes $(H)$ were recorded in $10 \mathrm{~mm} \mathrm{Ba}{ }^{2+}$ solutions. Also shown are data obtained using $2 \mathrm{mM} \mathrm{Ca}^{2+}$ as the charge carrier from HEK-293 cells stably transfected with $\alpha 1 \mathrm{I}(I)$. Smooth curves represent Boltzmann fits to the all the activation data points and to inactivation data points that were $>50 \%$.

used a tail current protocol that increases the probability of channel opening at negative potentials where the driving force is larger, and hence the currents are larger. Representative sweeps were chosen to illustrate that channel openings occur in bursts and to show the presence of a subconductance state (Fig. 7A). The third trace in Figure $7 A$ shows a channel closing from the full to a subconductance state, whereas traces 4 and 6 show openings to the subconductance state. The data were idealized with the Transit algorithm (VanDongen, 1996), and the amplitude of the
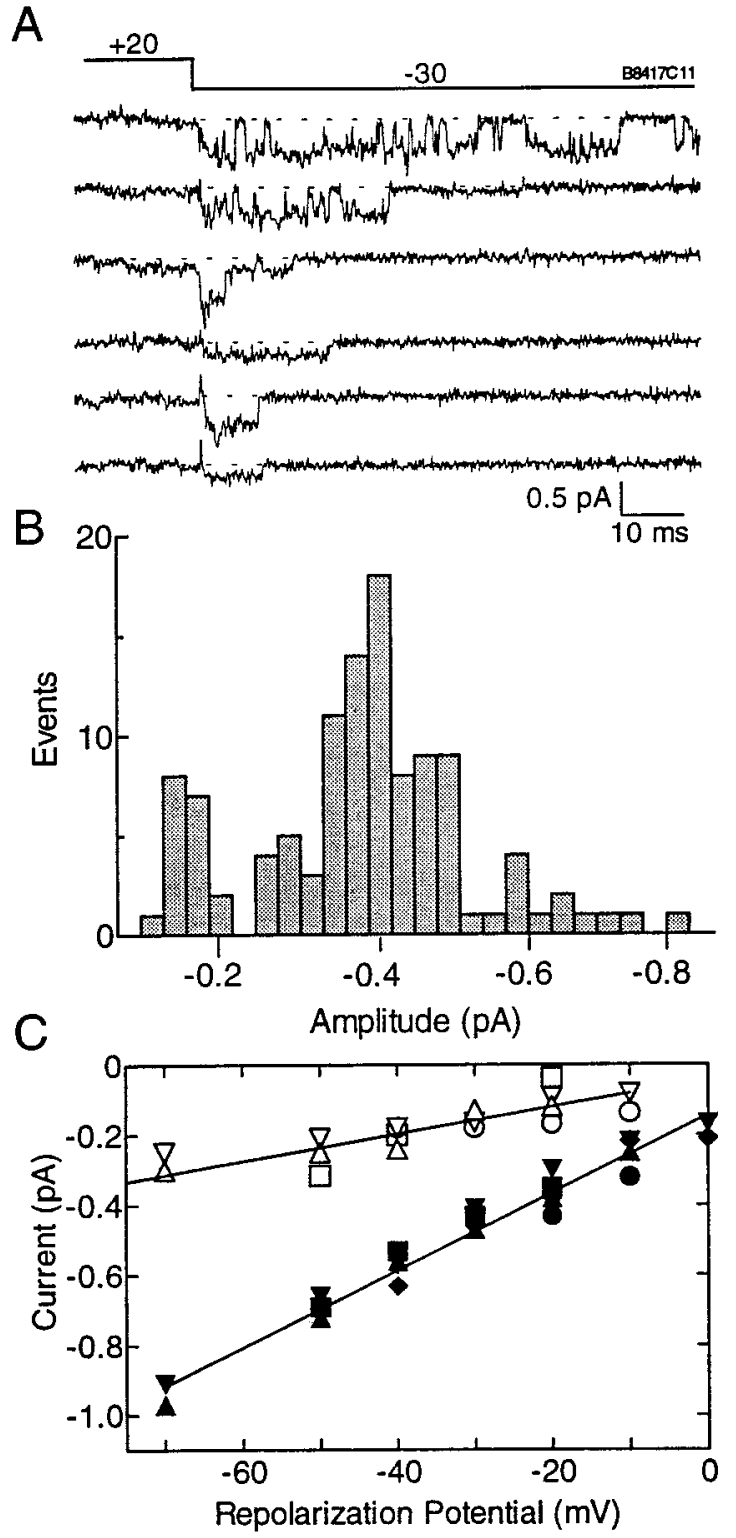

Figure 7. Single-channel currents of $\alpha 1$ I measured from Xenopus oocytes using the cell-attached patch-clamp method. $A$, Representative traces from a single patch displaying full and subconductance openings of $\alpha 1 \mathrm{I}$. The voltage protocol contained a prepulse to $+20 \mathrm{mV}$ followed by a test pulse to $-30 \mathrm{mV}$. $B$, Channel openings and closings were idealized using Transit to determine the amplitude of channel openings. Data are taken from the same patch shown in $A$. $C$, Single-channel conductance of $\alpha 1 \mathrm{I}$ currents. The amplitudes of single channels were obtained from Gaussian fits to amplitude histograms of idealized openings. The amplitudes were plotted against test potential. Slope conductances were calculated by linear regression through all the data points. Data were obtained from five patches on four oocytes. Filled symbols represent full conductance states, whereas open symbols represent subconductance states measured from the same patch.

idealized openings were plotted in Figure $7 B$. This plot showed that channels opened to two distinct amplitudes. Gaussian fits to these histograms were used to determine the amplitude of the openings, then plotted as a function of repolarization potential. The data were then fit by linear regression to determine the slope conductance. The conductance of the small openings was $3.9 \pm$ $0.5 \mathrm{pS}$, whereas the larger openings had a conductance of $11.0 \pm$ 
$0.5 \mathrm{pS}$. The current at $0 \mathrm{mV}$ for the full conductance state was $-0.15 \mathrm{pA}$.

\section{DISCUSSION}

The present study describes the cloning and expression of a novel member of the T-type $\mathrm{Ca}^{2+}$ channel family. Discovery of this family of genes was made possible by the development of normalized cDNA libraries (Soares et al., 1994), systematic sequencing of clones from these libraries, and free access to their DNA sequences (Lennon et al., 1996). We cloned the first cDNA fragment of $\alpha 1 \mathrm{I}$ by low-stringency screening of a rat brain cDNA library with two IMAGE Consortium clones that encoded either $\alpha 1 \mathrm{G}$ or $\alpha 1 \mathrm{H}$. The cloning project was greatly facilitated by efforts to sequence the human genome, in particular the work performed by the Wellcome Trust Genome Campus, which led to partial sequencing of the human $\alpha 1 \mathrm{I}$ gene, $C A C N A 1 I$, and its localization on human chromosome 22q12.3-13.2.

Sequence homology can be used to subdivide the family of voltage-gated $\mathrm{Ca}^{2+}$ channel $\alpha 1$ subunits into three subfamilies: (1) T-type (G, H, I); (2) L-type (S, C, D, F); and (3) non-L-type HVA (A, B, E). Electrophysiological characterization of these cloned channels has revealed considerable functional differences between the members of each subfamily. For example, $\alpha 1 \mathrm{~S}$ encodes a slow $\mathrm{Ca}^{2+}$ channel (Perez-Reyes et al., 1989), whose main physiological role is as a voltage sensor, coupling depolarization to skeletal muscle contraction (Stern et al., 1997). Similarly $\alpha 1 \mathrm{E}$ has unique characteristics of inactivation gating and permeation that set it apart from $\alpha 1 \mathrm{~A}$ and $\alpha 1 \mathrm{~B}$ (Soong et al., 1993; Bourinet et al., 1996). In the T-type subfamily, it is $\alpha 1 \mathrm{I}$ that stands apart. It encodes a slowly activating and inactivating $\mathrm{Ca}^{2+}$ channel that gates in voltage ranges similar to, but higher than the other two cloned $\mathrm{T}$ channels. It can be classified as a T-type channel by virtue of its slowly deactivating tail currents and tiny singlechannel conductance in $115 \mathrm{mM} \mathrm{BaCl}_{2}$.

The deduced amino acid sequence of $\alpha 1 \mathrm{I}$ is $\sim 58 \%$ identical to either $\alpha 1 \mathrm{G}$ or $\alpha 1 \mathrm{H}$, but only $\sim 15 \%$ identical to the HVA $\alpha 1$ subunits. The regions of least conservation between the T-type channels are their intracellular loops. The III-IV linker is an exception because it is $75 \%$ identical among the three $\mathrm{T}$ channel proteins. Perhaps this high degree of sequence identity is caused by conservation of function as observed in voltage-gated $\mathrm{Na}^{+}$ channels where the III-IV linker plays a role in fast inactivation (Catterall, 1995). A role of the intracellular linkers in inactivation was postulated before the structure of $\mathrm{T}$ channels was even deduced (Miller and $\mathrm{Hu}, 1995)$.

Three major conclusions from our expression studies with $\alpha 1 \mathrm{I}$ are: one, it encodes a T-type $\mathrm{Ca}^{2+}$ channel with a unique voltage dependence; two, it encodes a slow channel; and three, its activity is dependent on the expression system. Expression in both heterologous expression systems demonstrated that $\alpha 1 \mathrm{I}$ encoded low voltage-activated currents. The threshold voltage for channel activation was $-60 \mathrm{mV}$ (in $10 \mathrm{mM} \mathrm{Ba}^{2+}$ ), which was similar to what we have observed for $\alpha 1 \mathrm{G}$ and $\alpha 1 \mathrm{H}$ (Cribbs et al., 1998; Perez-Reyes et al., 1998). Expression in Xenopus oocytes led to $\alpha 1 \mathrm{I}$ currents that were as slow as those observed for the L-type channels of skeletal muscle (Garcia et al., 1992). In contrast, $\alpha 1 \mathrm{I}$ currents from transfected HEK-293 cells activated and inactivated much more quickly. In addition, the voltage dependence of steady-state inactivation differed between these two expression systems, with the oocyte currents requiring $8 \mathrm{mV}$ higher depolarizations. The reason for this discrepancy is under investigation. A plausible explanation is that HEK-293 cells, or oocytes, express a subunit of T-type channels that can influence kinetics and steady-state inactivation. High voltage-activated $\mathrm{Ca}^{2+}$ channels are multisubunit complexes, which in addition to $\alpha 1$ subunits, also contain at least two and sometimes three auxiliary subunits, $\alpha_{2} \delta$, $\beta$, and $\gamma$. All of these subunits have been reported to modulate channel properties (Perez-Reyes and Schneider, 1994); by analogy, it is likely that LVA channels also have accessory subunits. It should be noted that HEK-293 cells were originally derived from human kidney (Graham et al., 1977), which is the tissue with the highest expression of $\alpha 1 \mathrm{H}$ (Cribbs et al., 1998). It is also interesting to speculate that the newly identified $\gamma 2$ subunit may be a T-type channel subunit (Letts et al., 1998). Mutations in the $\gamma 2$ gene are thought to be responsible for the absence epilepsy phenotype of the stargazer mouse. Similarly, it has been suggested that increased $\mathrm{T}$ channel activity may cause absence epilepsy in rats (Tsakiridou et al., 1995).

Three criteria can be used to define T-type channels, their opening at membrane potentials near the resting membrane potential of most cells (LVA), their slow closing after a depolarization (SD), and their tiny (T) single-channel conductance in saturating concentrations of $\mathrm{Ba}^{2+}$ (Matteson and Armstrong, 1986; Carbone and Lux, 1987; Fox et al., 1987). T-type channels also have a distinctive criss-crossing set of current traces obtained during the $I-V$ protocol (Randall and Tsien, 1997). Despite its slow kinetics, $\alpha 1$ I still produces this distinctive pattern. This pattern is the result of the voltage-dependence of $\mathrm{T}$ channel kinetics, where activation kinetics are determined by the latency to first opening and by an inactivation process that is tightly coupled to activation (Carbone and Lux, 1987; Droogmans and Nilius, 1989; Chen and Hess, 1990; Miller and Hu, 1995). Despite the slower activation kinetics than either $\alpha 1 \mathrm{G}$ or $\alpha 1 \mathrm{H}, \alpha 1 \mathrm{I}$ deactivates with a similar time course, producing a slow tail current. HVA channels, such as $\alpha 1 \mathrm{E}$, close at least sixfold faster. The exact mechanism by which $\mathrm{T}$ channels, which have a mean open time of $\sim 1 \mathrm{msec}$, produce such a slow tail has not been fully characterized.

One of the early methods for separating LVA from HVA currents was to record currents from holding potentials of -90 and $-40 \mathrm{mV}$, then subtract the currents. This was useful because in many cells only LVA currents inactivate at $-40 \mathrm{mV}$. Recent studies suggest that some HVA channels inactivate at lower potentials than LVA channels, notably the R-type (Randall and Tsien, 1997) and the cloned $\alpha 1 \mathrm{E}$ (Fig. 6). Therefore steady-state inactivation is no longer a defining feature of LVA channels. Among the cloned $\mathrm{T}$ channels, we find a $15 \mathrm{mV}$ difference between the subtypes, with $\alpha 1$ I requiring the highest prepulse potentials. Because activation of $\alpha 1 \mathrm{I}$ is also shifted to more depolarized potentials, this leads to its having the largest window currents among the three cloned T channels. Notably, this window current occurs very close to the resting membrane potential of most cells, suggesting that $\alpha 1 \mathrm{I}$ may play a role in determining resting concentrations of intracellular $\mathrm{Ca}^{2+}$. Window currents are an essential property of channels involved in pacemaker activity and play a critical role in the integration of synaptic potentials (Williams et al., 1997).

The single-channel conductance of native $\mathrm{T}$ channels ranges between 5 and 9 pS (Huguenard, 1996). Similarly, we found that $\alpha 1 \mathrm{G}$ had a single-channel conductance of $7.5 \mathrm{pS}$ and that $\alpha 1 \mathrm{H}$ was slightly smaller, 5.3 pS (Cribbs et al., 1998; Perez-Reyes et al., 1998). The conductance of $\alpha 1 \mathrm{I}$ was significantly larger (11 pS), approaching the value determined for rat $\alpha 1 \mathrm{E}, 12.5 \mathrm{pS}$ (Bourinet et al., 1996). In addition, rat $\alpha 1 \mathrm{E}$ conducts $\mathrm{Ba}^{2+}, \mathrm{Ca}^{2+}$, and $\mathrm{Sr}^{2+}$ 
equally, as observed for native T channels (Shuba et al., 1991). Although $\alpha 1 \mathrm{E}$ and $\alpha 1 \mathrm{I}$ have similar slope conductances, the single-channel amplitudes are very different at $0 \mathrm{mV}(\alpha 1 \mathrm{E},-0.5$ $\mathrm{pA} ; \alpha 1 \mathrm{I},-0.15 \mathrm{pA}$ ) because they have distinct reversal potentials. Evidence for the different reversal potentials was presented at the whole-cell level (Fig. 4B). Measurement of the conductance of cloned $\mathrm{T}$ channels is complicated by the presence of a subconductance state. Evidence that these smaller openings are caused by the cloned $\mathrm{T}$ channels and not an endogenous oocyte channel was the following: (1) endogenous $\mathrm{Ca}^{2+}$ channels were not detected at the whole-cell level in these batches of oocytes, (2) endogenous channels generate $-0.5 \mathrm{pA}$ current at $0 \mathrm{mV}$ (Lacerda et al., 1994), (3) transitions between the full and subconductance states are clearly visible (Fig. 7), and (4) both types of openings disappear when the holding potential is shifted to $-40 \mathrm{mV}$ (results not shown). The presence of subconductance states for native cardiac T channels (Droogmans and Nilius, 1989) and cloned HVA channels (Meir and Dolphin, 1998) have been noted.

The discovery of a clone encoding slow T-type channels may have been predicted from studies in native cells. Slow T-type channels have been described in neurons isolated from various rat thalamic nuclei, such as the reticular (Huguenard and Prince, 1992), laterodorsal (Tarasenko et al., 1997), and lateral habenula (Huguenard et al., 1993). They have also been described in a dorsal root ganglion-neuroblastoma hybrid cell line (Dolphin, 1998). These native T currents inactivated with nearly identical time constants as observed for $\alpha 1 \mathrm{I}$ (55 msec). We suggest that these slow $\mathrm{T}$ channels are encoded by $\alpha 1 \mathrm{I}$. Support for this hypothesis is provided by the expression of $\alpha 1 \mathrm{I}$ mRNA in these same brain regions (Talley et al., 1999). Notably, $\alpha 1 \mathrm{I}$ is abundantly expressed in the thalamic reticular nucleus and lateral habenula. In addition, slow thalamic T channels required stronger depolarizations for channel opening than the fast $\mathrm{T}$ currents (Huguenard and Prince, 1992; Tarasenko et al., 1997). Similarly, we find that $\alpha 1 \mathrm{I}$ gates at less negative potentials than either $\alpha 1 \mathrm{G}$ or $\alpha 1 \mathrm{H}$. One notable difference is that the slow thalamic T current inactivated at more negative potentials than the fast, whereas we find the opposite result. However, we also found that the voltage dependence of inactivation varied between expression systems, suggesting this property may be affected by auxiliary subunits. Injection of thalamic-hypothalamic mRNA into Xenopus oocytes has been reported to produce LVA channels (Dzhura et al., 1996). The relationship of these currents to $\alpha 1 \mathrm{I}$ is not clear, because these currents inactivated much more slowly.

Knowledge of the distribution and functional properties of the three $\mathrm{T}$ channels should lead to a greater understanding of their physiological roles. $\mathrm{T}$ channels are thought to play a pacemaker role in the genesis of rebound burst firing which, through reciprocal connections, can lead to oscillations and resonance of neuronal circuits (Huguenard, 1996). Burst firing of thalamic T channels is thought to be important in the transition to sleep and in the pathophysiology of epilepsy (McCormick and Bal, 1997). The ability of many antiepileptics to inhibit $\mathrm{T}$ channel activity led to the hypothesis that they may be involved in epilepsy (Coulter et al., 1990). Support for this hypothesis came from the observation that $\mathrm{T}$ channel activity of thalamic reticular neurons was increased 50\% in GAERS (Tsakiridou et al., 1995), a well defined rat model of absence epilepsy (Vergnes and Marescaux, 1994). Cloning of $T$ channels and the ability to express these channels at high density in stably transfected cells should provide an assay to study the pharmacological properties of $\mathrm{T}$ channels and may lead to the development of a new generation of antiepileptic drugs.

\section{REFERENCES}

Altschul SF, Gish W, Miller W, Myers EW, Lipman DJ (1990) Basic local alignment search tool. J Mol Biol 215:403-410.

Bech-Hansen NT, Naylor MJ, Maybaum TA, Pearce WG, Koop B, Fishman GA, Mets M, Musarella MA, Boycott KM (1998) Loss-offunction mutations in a calcium-channel $\alpha 1$-subunit gene in Xp11.23 cause incomplete $\mathrm{X}$-linked congenital stationary night blindness. Nat Genet 19:264-267.

Bourinet E, Zamponi GW, Stea A, Soong TW, Lewis BA, Jones LP, Yue DT, Snutch TP (1996) The $\alpha_{1 \mathrm{E}}$ calcium channel exhibits permeation properties similar to low-voltage-activated calcium channels. J Neurosci 16:4983-4993.

Carbone E, Lux HD (1987) Single low-voltage-activated calcium channels in chick and rat sensory neurones. J Physiol (Lond) 386:571-601.

Catterall WA (1995) Structure and function of voltage-gated ion channels. Annu Rev Biochem 64:493-531.

Chen CF, Hess P (1990) Mechanism of gating of T-type calcium channels. J Gen Physiol 96:603-630.

Chen J, DeVivo M, Dingus J, Harry A, Li J, Sui J, Carty DJ, Blank JL, Exton JH, Stoffel RH, Inglese J, Lefkowitz RJ, Logothetis DE, Hildebrandt J, Iyengar R (1995) A region of adenylyl cyclase 2 critical for regulation by $G$ protein $\beta \gamma$ subunits. Science 268:1166-1169.

Coulter DA, Huguenard JR, Prince DA (1990) Differential effects if petit mal anticonvulsants and convulsants on thalamic neurones: calcium current reduction. Br J Pharmacol 100:800-806.

Cribbs LL, Lee J-H, Yang J, Satin J, Zhang Y, Daud A, Barclay J, Williamson MP, Fox M, Rees M, Perez-Reyes E (1998) Cloning and characterization of $\alpha 1 \mathrm{H}$ from human heart, a member of the T-type calcium channel gene family. Circ Res 83:103-109.

DeWaard M, Scott VES, Pragnell M, Campbell KP (1996) Identification of critical amino acids involved in $\alpha_{1}-\beta$ interaction in voltage-dependent $\mathrm{Ca}^{2+}$ channels. FEBS Lett 380:272-276.

Dolphin AC (1998) Properties and modulation of T-type currents in dorsal root ganglia and ND7-23 cells: comparison with $\alpha 1 \mathrm{E}$ currents expressed in COS-7 cells. In: Low voltage-activated T-type calcium channels (Tsien RW, Clozel J-P, Nargeot J, eds), pp 269-278. Chester, UK: Adis International.

Droogmans G, Nilius B (1989) Kinetic properties of the cardiac T-type calcium channel in the guinea-pig. J Physiol (Lond) 419:627-650.

Durell SR, Hao Y, Guy HR (1998) Structural models of the transmembrane region of voltage-gated and other $\mathrm{K}^{+}$channels in open, closed, and inactivated conformations. J Struct Biol 121:263-284.

Dzhura IO, Naidenov VG, Lyubanova OP, Kostyuk PG, Shuba YM (1996) Characterization of hypothalamic low-voltage-activated $\mathrm{Ca}$ channels based on their functional expression in Xenopus oocytes. Neuroscience 70:729-738.

Ellinor PT, Zhang J-F, Randall AD, Zhou M, Schwarz TL, Tsien RW, Horne WA (1993) Functional expression of a rapidly inactivating neuronal calcium channel. Nature 363:455-458.

Fox AP, Nowycky MC, Tsien RW (1987) Single-channel recordings of three types of calcium channels in chick sensory neurones. J Physiol (Lond) 394:173-200.

Garcia J, McKinley K, Appel SH, Stefani E (1992) $\mathrm{Ca}^{2+}$ current and charge movement in adult single human skeletal muscle fibres. J Physiol (Lond) 454:183-196.

Graham FL, Smiley J, Russell WC, Nairn R (1977) Characteristics of a human cell line transformed by DNA from adenovirus type 5. J Gen Virol 36:59-72.

Hille B (1992) Ionic channels of excitable membranes. Sunderland, MA: Sinauer.

Huguenard JR (1996) Low threshold calcium currents in central nervous system neurons. Annu Rev Physiol 58:329-348.

Huguenard JR, Prince DA (1992) A novel T-type current underlies prolonged $\mathrm{Ca}(2+)$-dependent burst firing in GABAergic neurons of rat thalamic reticular nucleus. J Neurosci 12:3804-3817.

Huguenard JR, Gutnick MJ, Prince DA (1993) Transient Ca2+ currents in neurons isolated from rat lateral habenula. J Neurophysiol 70:158-166.

Jan LY, Jan YN (1990) A superfamily of ion channels. Nature 345:672.

Lacerda AE, Perez-Reyes E, Wei X, Castellano A, Brown AM (1994) T-type and N-type calcium channels of Xenopus oocytes: evidence for specific interactions with beta subunits. Biophys J 66:1833-1843. 
Lennon G, Auffray C, Polymeropoulus M, Soares MB (1996) The I.M.A.G.E. consortium: an integrated molecular analysis of genomes and their expression. Genomics 33:151-152.

Leonard JP, Snutch TP (1991) The expression of neurotransmitter receptors and ion channels in Xenopus oocytes. In: Molecular neurobiology: a practical approach (Chad J, Wheal H, eds), pp 161-182. Oxford: IRL.

Letts VA, Felix R, Biddlecome GH, Arikkath J, Mahaffey CL, Valenzuela A, Bartlett II FS, Mori Y, Campbell KP, Frankel WN (1998) The mouse stargazer gene encodes a neuronal $\mathrm{Ca}^{2+}$-channel $\gamma$ subunit. Nat Genet 19:340-347.

Liman ER, Tytgat J, Hess P (1992) Subunit stoichiometry of a mammalian $\mathrm{K}+$ channel determined by construction of multimeric cDNAs. Neuron 9:861-871.

Llinas R, Jahnsen H (1982) Electrophysiology of mammalian thalamic neurons in vitro. Nature 297:406-408.

Matteson DR, Armstrong CM (1986) Properties of two types of calcium channels in clonal pituitary cells. J Gen Physiol 87:161-182.

McCormick DA, Bal T (1997) Sleep and arousal: thalamocortical mechanisms. Annu Rev Neurosci 20:185-215.

Meir A, Dolphin AC (1998) Known calcium channel $\alpha_{1}$ subunits can form low threshold small conductance channels with similarities to native T-type channels. Neuron 20:341-351.

Methfessel C, Witzemann V, Takahashi T, Mishina M, Numa S, Sakmann B (1986) Patch clamp measurements on Xenopus laevis oocytes: currents through endogenous channels and implanted acetylcholine receptor and sodium channels. Pflügers Arch 407:577-588.

Miller A, Hu B (1995) A molecular model of low-voltage-activated calcium conductance. J Neurophysiol 73:2349-2356.

Murakami M, Wissenbach U, Flockerzi V (1996) Gene structure of the murine calcium channel $\beta 3$ subunit, cDNA and characterization of alternative splicing and transcription products. Eur $\mathrm{J}$ Biochem 236:138-143.

Ophoff RA, Terwindt GM, Frants RR, Ferrari M (1998) P/Q-type Ca ${ }^{2+}$ channel defects in migraine, ataxia and epilepsy. Trends Pharmacol Sci 19:121-127.

Perez-Reyes E, Schneider T (1994) Calcium channels: structure, function, and classification. Drug Dev Res 33:295-318.

Perez-Reyes E, Kim HS, Lacerda AE, Horne W, Wei XY, Rampe D, Campbell KP, Brown AM, Birnbaumer L (1989) Induction of calcium currents by the expression of the alpha 1-subunit of the dihydropyridine receptor from skeletal muscle. Nature 340:233-236.

Perez-Reyes E, Cribbs LL, Daud A, Lacerda AE, Barclay J, Williamson MP, Fox M, Rees M, Lee J-H (1998) Molecular characterization of a neuronal low voltage-activated T-type calcium channel. Nature 391:896-900.

Randall AD, Tsien RW (1997) Contrasting biophysical and pharmacological properties of T- type and R-type calcium channels. Neuropharmacology 36:879-893.

Sambrook J, Fritsch EF, Maniatis T (1989) Molecular cloning: a laboratory manual. Cold Spring Harbor, MA: Cold Spring Harbor Laboratory.

Schneider T, Wei X, Olcese R, Costantin JL, Neely A, Palade P, Perez-
Reyes E, Qin N, Zhou J, Crawford GD, Smith RG, Appel SH, Stefani E, Birnbaumer L (1994) Molecular analysis and functional expression of the human type $\mathrm{E} \alpha_{1}$ subunit. Receptors Channels 2:255-270.

Shuba YM, Teslenko VI, Savchenko AN, Pogorelaya NH (1991) The effect of permeant ions on single calcium channel activation in mouse neuroblastoma cells: ion-channel interactions. J Physiol (Lond) 443:25-44.

Soares MB, Bonaldo MDF, Jelene P, Su L, Lawton L, Efstratiadis A (1994) Construction and characterization of a normalized cDNA library. Proc Natl Acad Sci USA 91:9228-9232.

Soong TW, Stea A, Hodson CD, Dubel SJ, Vincent SR, Snutch TP (1993) Structure and functional expression of a member of the low voltage-activated calcium channel family. Science 260:1133-1136.

Stern MD, Pizarro G, Rios E (1997) Local control model of excitationcontraction coupling in skeletal muscle. J Gen Physiol 110:414-440.

Strom TM, Nyakatura G, Apfelstedt-Sylla E, Hellebrand H, Lorenz B, Weber BHF, Wutz K, Gutwillinger N, Ruther K, Drescher B, Sauer C, Zrenner E, Meitinger T, Rosenthal A, Meindl A (1998) An L-type calcium-channel gene mutated in incomplete X-linked congenital stationary blindness. Nat Genet 19:260-263.

Talley EM, Cribbs LL, Lee J-H, Daud A, Perez-Reyes E, Bayliss D (1999) Differential distribution of three members of a gene family encoding low voltage-activated (T-type) calcium channels. J Neurosci 19:1895-1911.

Tarasenko AN, Kostyuk PG, Eremin AV, Isaev DS (1997) Two types of low-voltage-activated $\mathrm{Ca} 2+$ channels in neurones of rat laterodorsal thalamic nucleus. J Physiol (Lond) 499:77-86.

Tsakiridou E, Bertollini L, de Curtis M, Avanzini G, Pape HC (1995) Selective increase in T-type calcium conductance of reticular thalamic neurons in a rat model of absence epilepsy. J Neurosci 15:3110-3117.

VanDongen AMJ (1996) A new algorithm for idealizing single ion channel data containing multiple unknown conductance levels. Biophys $\mathrm{J}$ 70:1303-1315.

Vergnes M, Marescaux C (1994) Pathophysiological mechanisms underlying genetic absence epilepsy in rats. In: Idiopathic generalized epilepsies: clinical, experimental, and genetic aspects (Malafosse A, Genton P, Hirsch E, Marescaux C, Broglin D, Bernasconi R, eds), pp 151-168. London: John Libbey \& Co.

Williams ME, Marubio LM, Deal CR, Hans M, Brust PF, Philipson LH, Miller RJ, Johnson EC, Harpold MM, Ellis SB (1994) Structure and functional characterization of neuronal alpha $1 \mathrm{E}$ calcium channel subtypes. J Biol Chem 269:22347-22357.

Williams SR, Toth TI, Turner JP, Hughes SW, Crunelli V (1997) The "window" component of the low threshold $\mathrm{Ca} 2+$ current produces input signal amplification and bistability in cat and rat thalamocortical neurones. J Physiol (Lond) 505:689-705.

Wilson DL, Morimoto K, Tsuda Y, Brown AM (1983) Interaction between calcium ions and surface charge as it relates to calcium currents. J Membr Biol 72:117-130.

Zamponi GW, Bourinet E, Snutch TP (1996) Nickel block of a family of neuronal calcium channels: subtype- and subunit-dependent action at multiple sites. J Membr Biol 151:77-90. 